Review

\title{
Antimicrobial Dressing for Diabetic Foot Ulcer Colonized with MRSA
}

\author{
Parthasarathy Ravichandran and Sai Prasad Chitti \\ Department of Biochemistry and Molecular Biology, Pondicherry University, Pondicherry, India
}

Article history

Received: $24-05-2015$

Revised: 26-07-2015

Accepted: 02-11-2015

Corresponding Author: Parthasarathy Ravichandran Department of Biochemistry and Molecular Biology, Pondicherry University, Pondicherry, India

Email: sarathi.rps@gmail.com

\begin{abstract}
Wound healing in patients with diabetic foot ulcer differs among people. The wound healing process was influenced by factors like nature of the wound, tissue and an immunity of a person. Any measure taken to control bacterial colonies in wound plays a significant role in wound healing. However, recent emergence of Methicillin-resistant Staphylococcus Aureus (MRSA) associated with chronic wounds created health concerns worldwide. An MRSA colony present in diabetic wounds vulnerable to prolong the wound healing has reported worldwide. Since MRSA are resistant to a wide range of antibiotics, choosing appropriate dressings to treat MRSA colonized wounds has become a challenge. Either synthetic or natural antimicrobial agents are used to develop dressings that combat against MRSA infections. In today's practice, the incidence of chronic wounds and its associated socioeconomic consequences is rising despite effort and advances in wound management. In this review, an attempt made to summarize various antimicrobial dressings based on its activity against MRSA.
\end{abstract}

Keywords: Wound, Honey, Silver, Antimicrobial, MRSA

\section{Introduction}

The estimated prevalence of diabetes covers 382 million people (Tao et al., 2015). Initially, the diabetic foot was recognized in 19th century, however clinician's attention towards the matter was turned only after last half of the 20th century (Boulton, 2008; Connor, 2008). Any foot ulcer is potentially dangerous in diabetic patients (Boulton et al., 2005). In their lifetime, about $15 \%$ of diabetic patients develop Diabetic Foot Ulcer (DFUs) (Kandemir et al., 2007). Worldwide, the prevalence of the diabetic foot accounts for around $20 \%$ of hospital admissions (Roberts and Simon, 2012). Diabetes with a complication of DFUs is estimated with high morbidity and mortality rate (Boulton, 2008).

Ischemia, neuropathy and infection are the major pathologies leading to DFUs (Brem and Tomic-Canic, 2007; Boulton, 2008; Connor, 2008). Decreased vascular supply and impaired host immune response promoted bacterial infection in DFU (Roberts and Simon, 2012). Although diabetic foot infections are polymicrobial, the most frequently isolated species is Staphylococcus aureus (Lipsky, 2008; Mendes et al., 2012) which is responsible for causing a wide range of illnesses (Murali et al., 2014). Penicillin and its derivatives, including Methicillin are used for the treatments of infections caused by Staphylococcus aureus (Rayner and Munckhof, 2005). The misuse and overuse of antibiotics against Staphylococcus aureus aids these microbes become resistant to drugs.

Staphylococcus aureus which is resistant to normal antimicrobial drugs such as chloramphenicol, tetracycline, amino glycosides and macrolides was referred to as Methicillin-resistant Staphylococcus aureus (MRSA) (Lee, 2003). It is reported that a mecA gene which codes for penicillin-binding protein named PBP $2 \mathrm{~A}$ is responsible for the resistance against Methicillin (Wielders et al., 2002). Lately, another gene named mecC resistance against Staphylococcus aureus was described and isolated in humans (Porrero et al., 2014).

Recently, the amount of MRSA infections are increasing worldwide (Dang et al., 2003; Lipsky, 2008). It is estimated about $46 \%$ of Staphylococcus aureus isolated are MRSA (Tentolouris et al., 2006). In diabetic wounds, presence of MRSA differs from $15-30 \%$ (Shankar et al., 2005). Patients with DFUs are extremely at a risk of infections. Once the wound is infected with bacteria, it spreads and ends up in severe destruction of tissues which results in amputation (Kandemir et al., 2007; Mendes et al., 2012; Zubair et al., 2012). In 
diabetes, foot ulceration and amputation are closely inter-related (Boulton, 2008). Foot ulceration and infection are the leading risk factors for amputation (Carmona et al., 2005). Approximately 15\% of patients with DFUs lead to lower extremity amputation. Additionally, MRSA dwell in surrounding atmosphere and hands of health care workers is a key mode of transmission between patients. Thus, MRSA have a high epidemic potential. Wound infection occurs when the microorganisms present in the wound overwhelm the immune system of the person (Robson, 1997). Prevention and treatment are necessary to prevent morbidity, particularly amputation (Lipsky et al., 2004).

DFU infection followed by amputation not only increases the morbidity (Centers for Disease and Prevention, 2003). Additionally, the psychological impact of an amputation dramatically increases the risk of mortality. Diabetic foot ulcers are the common and costly complications of diabetes (Ramsey et al., 1999). Previous studies have examined the prevalence of diabetic foot wounds (Dang et al., 2003), however this prospective study examined the prevalence of diabetic foot wounds infected with MRSA.

\section{Role of Dressings}

An ideal wound care dressings for DFUs should maintain a moist wound healing environment, remove excessive exudate, odor and be effective in treating infection of diabetic foot wounds. The exact level to discriminate bacterial infection from bacterial colonization is not clear. However, it is established that bacteria equal to or greater than $10^{5}$ colony forming units per gram of tissue (cfu/g) is sufficient to confirm infection (Sibbald et al., 2003). Dressing materials incorporated with various antimicrobial compounds such as silver, honey, iodine are in use for millennia. In the early $20^{\text {th }}$ century, the discovery of antibiotics greatly reduced the routine usage of such compounds. More recently, the interest in these compounds has renewed. Manufacturers add these compounds to the dressings, which provide greater antimicrobial action and aid in healing process. Wound dressing products containing these agents have developed to address the needs of chronic wounds with the intent to minimize colonization to prevent local infection, thereby enhancing healing. Some of these products outlined in this review.

\section{Dressing Methods with Natural Antimicrobial Agent}

\section{Honey}

In traditional medicine, honey had valued place over centuries (Chowdhury, 1999). Honey used for rapid clearance of bacteria in colonized and infected wounds (Efem, 1988; Vardi et al., 1998). It also removes malodor associated with wounds (Efem, 1988; Subrahmanyam, 1991; Molan, 2002) and promotes autolytic debridement to facilitate the rapid development of a clean, granulating wound bed (Subrahmanyam, 1998). A rapid rate of healing has been reported in chronic wounds treated with honey (Efem, 1988; Wood et al., 1997). Continuous application of honey for 7-10 days enhances sterility in infected wounds as reported earlier (Efem, 1988). Honey exhibits broad-spectrum antimicrobial activity against more than 80 species (Molan, 1992; Blair and Carter, 2005). Honey has a complex chemistry and its activity varies markedly based on its source (Molan, 1992). Depending on the floral source, climate and harvesting conditions the antimicrobial properties of a honey also varies (Molan, 1992; French et al., 2005). However, almost all-natural honey contains flavonoids, phenolic acids, Superoxide Dismutase (SOD), Reduced Glutathione (GSH), Millard reaction products and peptides. Most of antioxidant effect exhibited by these compounds is because of its synergistic properties (Alvarez-Suarez et al., 2010). Many studies illustrating the antimicrobial activity of honey have been published (Al-Waili and Haq, 2004; Blair and Carter, 2005; Molan, 2006).

\section{Mechanism of Action}

The precise mode of action of honey has not yet been fully understood, but acidity, osmolarity, generation of hydrogen peroxide and other phytochemical components such as alkaloids, flavonoids are considered important for its antimicrobial activity (Molan, 1992; 1999). Four major properties of honey were responsible for its antimicrobial activity. Initially, honey dehydrates bacteria by withdrawing the moisture out of wound environment. The high sugar content of honey is also hinders the growth of a microbe. But the inhibitory effect of honey on bacteria is independent of its sugar content (Cooper et al., 2002a; 2002b). The high osmolarity of honey protects the skin from maceration and its high viscosity prevents cross-infection of wounds (Bergman et al., 1983; Efem, 1988; Subrahmanyam, 1991; Moore et al., 2001; Molan, 2006). Secondly, the honey is acidic in nature at a $\mathrm{pH}$ range between 3.2 and 4.5 , which inhibit the growth of bacteria. Thirdly when honey is diluted, it continuously produce hydrogen peroxide by an enzymatic action of glucose oxidize which inhibits bacterial growth (Al-Waili and Haq, 2004; Eddy and Gideonsen, 2005; Molan, 2006). It is reported that the honey is capable of inhibiting common wound infecting bacteria species including Staphylococcus aureus even when diluted 10 times or more (Cooper et al., 1999). The minor contribution by several phytochemical factors is also responsible for 
antimicrobial activity (Al-Waili and Haq, 2004). The presence of unidentified phytochemical in honey is responsible for its high antimicrobial effect which is also resistant to heat and light (Molan, 1992; Olaitan et al., 2007). All these physical and chemical factors give honey unique property to act as a wound dressing (Basualdo et al., 2007).

Honey is of three types namely hydrogen peroxide honey (Pasture honey), non-peroxide honey (Manuka honey) and artificial honey. Based on its concentration honey can act as either bactericidal or bacteriostatic in nature. Pasture honey (4-8\%) and Manuka honey (5-11\%) were bacteriostatic whereas bactericidal at 5-10 and 8$15 \%$ (v/v) concentrations, respectively. Whereas, artificial honey (sugar solution) was bacteriostatic at a concentration of $20-30 \%$ and does not exhibit any bactericidal effect (Mandal and Mandal, 2011). Previously, a number of in vitro studies demonstrated the antimicrobial activity of honey against MRSA (Maeda et al., 2008). The MRSA strains were more sensitive to Manuka honey due to the presence of methyiglyoxal which is the dominant active antimicrobial component (Adams et al., 2009). The mean minimum inhibitory concentration values of Manuka and Pasture honey against MRSA (6.9 and $7.1 \% \mathrm{v} / \mathrm{v}$, respectively) (Cooper and Molan, 1999). In vitro clinical isolates of Methicillin-susceptible and Methicillin-resistant staphylococci were shown to be equally susceptible to Manuka honey with minimum inhibitory concentration reported as 3\% (v/v) (Cooper et al., 1999; 2002).

In staphylococci, alt gene 17 encodes for Murein hydrolases enzyme that is highly sensitive to manuka honey. A deficiency in these enzyme leads to failure in cell separation (Rice et al., 2003). It is reported that exposure of Staphylococcus aureus with $10 \%(\mathrm{w} / \mathrm{v})$ manuka Honey for period of $4 \mathrm{~h}$ found to interrupt the cell cycle during cytokinesis (Jenkins et al., 2011).

Dressing procedure with honey was generally less painful (Subrahmanyam, 1991). This is due to the ability of the honey to maintain the moisture of the wounds without adhesion to the granulating surface. The clinical use of honey has been its success in eradicating MRSA from colonized chronic wounds (Eddy and Gideonsen, 2005; Visavadia et al., 2008). It has used successfully on DFU patients who was threatened with amputation (Eddy and Gideonsen, 2005).

DFUs usually take a longer time to heal. For this reason, the affordability for the treatment was an issue. Therefore, the overall cost for wound dressing with honey is relatively cheaper and hence it does provide an economical and practical option for the management of wound ulcers in diabetic patients.

\section{Chitosan}

Chitosan is a polymer obtained from the shells of crustaceans which is highly biocompatible and biodegradable (Foda et al., 2007; Lee et al., 2009; Jayakumar et al., 2011). The bacteriostatic and fungistatic properties of chitosan are particularly useful in the wound care management (Sun and Li, 2011). Chitosan incorporated dressings used in the wound management system because of their unique properties like biocompatibility, biodegradability, non-toxic nature etc.

\section{Mechanism of Action}

It works by creating a positive charge, hence interacting with negatively charged molecules such as gram-positive bacteria, blood cells, proteins and lipids (Lee et al., 2009). Chitosan also has an accelerating effect on wound healing (Jayakumar et al., 2011) by activating immune cells through its cytokine production, giant cell migration and stimulating type IV collagen synthesis (Mezzana, 2007).

KytoCel is an absorbent dressing composed of natural, biodegradable acylated chitosan fibers. These fibers bond with wound exudate to form a clear gel that locks-in fluid and absorbs pathogens. The absorbent properties of KytoCel enable it to bind and lock away commonly encountered wound pathogens such as Escherichia coli, Staphylococcus aureus, Candida albicans and MRSA, thereby reducing wound bioburden and the risk of cross-contamination at dressing change (Li et al., 1992; Khor and Lim, 2003; Foda et al., 2007).

\section{Maggots}

Several ancient tribes and Mayan healers use maggots (Luciliasericata) to treat chronic wounds (Parnés and Lagan, 2007). Maggot therapy removes dead tissues in order to promote healing (Mumcuoglu, 2012). It is also known as larval therapy, biosurgery, therapeutic myiasis, Maggot Debridement Therapy (MDT), bio debridement (Singh et al., 2014). However, its use was declined in late 1900s due to introduction of antibiotics and surgical procedures in the treatment of wound (Chan et al., 2007).

\section{Mechanism of Action}

Use of maggots is helpful in achieving wound disinfection (Sherman et al., 2007; Tantawi et al., 2007), wound healing (Horobin et al., 2006) and biofilm inhibition. Maggot feeds on dead tissues, exudates and cell debris in the wound (Parnés and Lagan, 2007). Disinfection of wound achieved by ingestion of bacteria from infected tissues. Maggots secrete proteolytic enzymes that include collagenase (Ziffren et al., 1953) and trypsin and chymotrypsin like enzymes which aid in lysis of dead tissue and bacteria (Steenvoorde et al., 2005). Other alkaline medium containing calcium, urea and ammonium 
bicarbonate also secreted by maggots that further inhibit bacteria growth (Chan et al., 2007). A number of studies demonstrated that all microorganisms were eradicated within 10-15 $\mathrm{min}$ after ingestion by the maggot (Simmons, 1935).

The primary purpose of maggot therapy is the breakdown of necrotic tissue and transform into an acute wound (Beasley and Hirst, 2004). A study by Courtenay suggested that maggot therapy is an extremely efficient alternative option for fast and efficient wound management (Courtenay et al., 2000). Although, maggot therapy promoted wound healing in few studies, its effectiveness compared to other standard therapy is still under argument (Beasley and Hirst, 2004). There is limited literature on patient experiences on maggot therapy.

\section{Dressing Methods with Synthetic Antimicrobial Agent}

\section{Iodine}

In 1839, Davies first used aqueous potassium iodine. Later, Iodine used in aqueous and alcoholic preparations for hand washing and skin preparation prior to surgery (Leaper and Durani, 2008). However, earlier use of iodine resulted in undesired side effects such as skin irritation and staining. It is toxic, but dose-dependent is not harmful to humans but will be detrimental to bacteria (Leaper and Durani, 2008).

\section{Mechanism of Action}

Molecular iodine is active against bacteria, fungi and viruses. Iodine's exact antimicrobial mode of action is not fully understood, but it is believed to be associated with its ability to rapidly penetrate the cell wall of microorganisms and denature proteins, nucleotides and fatty acids leading to cell death (Chang, 1971; McDonnell and Russell, 1999). Iodine denatures proteins and enzymes by binding to thiol and sulphydryl groups and alters phospholipid membrane structures by blocking hydrogen bonding (Leaper and Durani, 2008).

Iodine released from the dressing transported by blood, which is readily absorbed in thyroid. Therefore, use of iodine-based dressings has declined because of its toxic effects (Simon et al., 2009). However, it believed that the development of products such as cadexomer iodine has reduced the number of iodine-associated toxicity cases (Michaels et al., 2009). In addition, it has suggested that the overall risk of toxicity to normal patients is minimal, but caution should be taken with children, pregnant or lactating women, patients with previously existing thyroid dysfunction or extensive burns (Leaper and Durani, 2008).
Iodine dressings based on its physical characteristics exists in two distinct forms cadexome iodine and Povidone iodine. Cadexomer iodine is a starch lattice that contains $0.9 \%$ iodine micro beads (Sundberg and Meller, 1997). A sustained release of iodine from cadexomer iodine exhibit antimicrobial activity by absorbing excess exudates in the wound bed (Fleck, 2006). Povidone iodine is an iodophor which is referred as polyvinylpyrrolidone iodine (PVP-I). PVP-I is composed of hydrophilic elemental iodine and a synthetic polymer (Mayer and Tsapogas, 1993). PVP-I on microbial cells affects the structure and functions of cellular proteins by blocking hydrogen bonding and altering the membrane structure (Cooper, 2004). Both cadexomer iodine and PVP-I area highly effective against MRSA. Lacey and Catto (1992) determined that more than $99 \%$ of MRSA cells were killed within $10 \mathrm{sec}$ of exposure to Povidone-iodine. Mertz et al. (1999) found that Cadexomer iodine significantly reduced MRSA. Effectiveness of Cadexomer iodine, in vivo against Staphylococcus aureus and MRSA was also established (Percival et al., 2005).

\section{Silver}

In medical field, the usage of silver was documented for the past thousands of years (Sinclair and Ryan, 1993; Thomas and McCubbin, 2003a). The use of Silver Nitrate (AgNO3) to treat ulcers was demonstrated in 18th century (Klasen, 2000). In 1920s, the use of colloidal silver in wound management was accepted by the US Food and Drug Administration (FDA) (Demling and Desanti, 2001). However, after the introduction of penicillin in the 1940s, antibiotics became the standard treatment for bacterial infections and the use of silver diminished. More recently, clinicians have turned back to silver for wound dressings because of the emergence and increase of antibiotic-resistant bacteria like MRSA (Gemmell et al., 2006).

Silver contained dressings are available in a variety of forms such as foams and hydrocolloids constituting free silver ions as the active ingredient (Ovington, 2001). The potency of silver as an antimicrobial agent was found to be depends on the amount and rate of free silver released onto the wound bed (Lansdown, 2002). Silver dressings may contain different forms of silver such as; silver nitrate, silver ions or silver-based crystalline nanoparticles (Bradshaw, 2011). The exact composition of these dressings was difficult to determine because many of the manufacturers would not disclose their product ingredients. It has suggested that elemental silver has little or no antimicrobial activity. However, its cationic form is highly active. In the presence of wound exudate, silver readily ionized to form cations (Lansdown, 2004). But the amount of silver released from the dressing differs 
between manufactures (Lansdown, 2004). The amount and rate of free silver released onto the wound surface will influence its antimicrobial activity and Lansdown has reported that levels in excess of $20 \mathrm{mg} / \mathrm{L}$ demonstrate the best results (Lansdown, 2002).

Silver is more universally effective against the growth of fungi, viruses, yeast, gram negative and gram-positive bacteria including MRSA. At particular concentrations, ionic silver kills detrimental microbes without affecting the proliferating granulation tissue (Forrest, 1982). Research has shown silver dressings are effective against MRSA (Maple et al., 1992; Russell et al., 1994; Wright et al., 1998; Fleck, 2006). Loh et al. (2009) tested MRSA isolated from wounds for known silver resistance genes and although these were identified in some of the isolates, all strains were found to be susceptible to the silver dressing used (Bradshaw, 2011). Both nanocrystalline silver, as well as ionic silver showed similar antimicrobial efficacy on in vitro testing. There has been a lot of variation in the test methods used to determine silver concentration in numerous publications. There appears to be no standard technique (Maple et al., 1992).

\section{Mechanism of Action}

In acidic environment of wound, silver ions converted to positive charged ionic salts and attracted towards negatively charged bacterial cell membrane, mediating the passage of silver into the bacterial cell (Lansdown, 2002; Brett, 2006; Michaels et al., 2009). The interaction of silver salt with bacterial thiol (2SH) groups leads to inactivation, the blocking of key pathways such as cellular respiration and structural changes in the bacterial membrane and the blocking of enzyme and transport systems (Bradshaw, 2011). Silver bind to tissue proteins and disturb the cell membrane leading to the bacterial death. Silver also bind and denature the bacterial DNA and RNA, thus inhibiting cell replication (Tredget et al., 1998; Wright et al., 1998; Yin et al., 1999; Lansdown, 2002; Fong and Wood, 2006).

In market a wide range of silver-based dressings are available with different therapeutic options. Some studies have demonstrated that silver is significantly cytotoxic towards fibroblasts and keratinocytes an essential components involved in wound repair (Burd et al., 2007; Du Toit and Page, 2009). Sustained release of silver is essential to achieve wound healing. Acticoat, one of the silver dressing when moistened with sterile water and placed on the wound releases clusters of highly reactive silver cations up to 100 parts per million, causing block in electron transport leading to inactivation of bacterial cell DNA and cell membrane damage (Dritch et al., 1987; Ovington, 2001; Lansdown,
2002). Acticoat 7 active against MRSA was demonstrated (Thomas and McCubbin, 2003b).

\section{PHMB}

Polyhexamethylenebiguanide (PHMB) has used as an antimicrobial agent for about 60 years including contact lens solution and pool cleaning. Recently, PHMB dressings introduced into wound management successfully. A wide range of PHMB dressings are available in market including gauze, drains and intravenous sponges and hydrogels (Motta and Trigilia, 2005; Moore and Gray, 2007). The PHMB molecule either chemically bound to dressing material or delivered freely into the wound tissues.

\section{Mechanism of Action}

The chemical structure of PHMB molecule is similar to the structure of Antimicrobial Peptides (AMPs). AMPs are produced by keratinocytes and inflammatory neutrophils to protect the wound infection (Sørensen et al., 2003). AMPS works by interfering with the cell metabolism of microorganisms, preventing them from absorbing nutrients and disposing of waste products, which ultimately results in microorganism death while the host cells remain unaffected. It is believed that PHMB molecule and AMPs possess the same mechanism of action because of its structural similarity (Moore and Gray, 2007). The PHMB component of the dressing has a proven broad-spectrum action with efficacy against bacteria, fungi and yeasts (Mueller and Krebsbach, 2008; Müller and Kramer, 2008), but it does not have an adverse effect on healthy host cells (Larkin et al., 1992; Moore and Gray, 2007; Gilliver, 2009).

A test of PHMB for biocompatibility resulted in less damage to healthy wound cells compared to other antimicrobial agents such as chlorhexidine, Povidoneiodine, triclosan, silver and sulfadiazine (Müller and Kramer, 2008). Suprasorb X+PHMB also successfully used to manage a MRSA-infected foot ulcer patient (Easy, 2015).

\section{Conclusion}

Diabetes is a metabolic disorder affecting function of a tissue. The individual with such metabolic disorder develop diabetic foot ulcers at certain part of their life, which is chronic in nature. The chronicity of diabetic foot ulcer increased with the presence of infectious microbes. Worldwide, an increase in antibiotic resistant bacteria such as MRSA had put the diabetic foot ulcer patient at high risk. To overcome these issues, selecting an appropriate dressing material is essential to reduce the morbidity and mortality of the patients. Compounds such as honey, iodine, PHMB and silver incorporated into dressings to provide antimicrobial 
action and aid the healing process. Selecting an appropriate dressing material for diabetic foot ulcer colonized with MRSA is somewhat challenging because each product has its own benefits and drawbacks. Dressing choice depends on relative size and nature of the wound. Much of the published literature on the antimicrobial properties of silver, honey, PHMB, chitosan and iodine-containing dressings is contradictory, with varying degrees of efficacy reported. The mechanisms of action of these compounds are yet poorly understood. Further studies are required to determine the mode of action of these compounds, which is promising in the development of new antimicrobial dressings.

\section{Acknowledgement}

The authors like to thank Dr. G. Nirmal Kumar, PostDoctoral Fellow, School of Energy and Environment, City University of Hong Kong, Hong Kong for reviewing the article.

\section{Funding Information}

The cost and related expenditure were covered by the corresponding author.

\section{Author's Contributions}

Parthasarathy Ravichandran: Contributed to the acquisition, analysis and interpretation of the data. Drafted final approval of the version to publish.

Sai Prasad Chitti: Contributed sustainably to the design of study. Provided critical revision of the manuscript.

\section{Ethics}

All authors have read and approved the manuscript and declare that there is no conflict of interest.

\section{References}

Adams, C.J., M. Manley-Harris and P.C. Molan, 2009. The origin of methylglyoxal in new Zealand Manuka (Leptospermum scoparium) honey. Carbohydrate Res., 344: 1050-1053. DOI: 10.1016/j.carres.2009.03.020

Alvarez-Suarez, J.M., S. Tulipani, S. Romandini, E. Bertoli and M. Battino, 2010. Contribution of honey in nutrition and human health: A review. Mediterranean J. Nutr. Metabolism, 3: 15-23. DOI: $10.3233 / \mathrm{s} 12349-009-0051-6$

Al-Waili, N.S. and A. Haq, 2004. Effect of honey on antibody production against thymus-dependent and thymus-independent antigens in primary and secondary immune responses. J. Med. Food, 7: 491-494. DOI: 10.1089/jmf.2004.7.491
Basualdo, C., V. Sgroy, M.S. Finola and J.M. Marioli, 2007. Comparison of the antibacterial activity of honey from different provenance against bacteria usually isolated from skin wounds. Vet. Microbiol., 124: 375-381. DOI: 10.1016/j.vetmic.2007.04.039

Beasley, W.D. and G. Hirst, 2004. Making a meal of Mrsa-the role of biosurgery in hospital-acquired infection. J. Hospital Infect., 56: 6-9.

DOI: 10.1016/j.jhin.2003.09.002

Bergman, A., J. Yanai, J. Weiss, D. Bell and M.P. David, 1983. Acceleration of wound healing by topical application of honey: An animal model. Am. J. Surgery, 145: 374-376. DOI: 10.1016/0002-9610(83)90204-0

Blair, S.E. and D.A. Carter, 2005. The potential for honey in the management of wounds and infection. Healthcare Infect., 10: 24-31. DOI: $10.1071 / \mathrm{HI} 05024$

Boulton, A.J.M., 2008. The diabetic foot: Grand overview, epidemiology and pathogenesis. Diabetes/Metabolism Res. Rev., 24: S3-S6. DOI: $10.1002 /$ dmrr.833

Boulton, A.J.M., L. Vileikyte, G. Ragnarson-Tennvall and J. Apelqvist, 2005. The global burden of diabetic foot disease. Lancet, 366: 1719-1724. DOI: 10.1016/S0140-6736(05)67698-2

Bradshaw, C.E., 2011. An in vitro comparison of the antimicrobial activity of honey, iodine and silver wound dressings. Bios. Horizons, 4: 61-70. DOI: 10.1093/biohorizons/hzr008

Brem, H. and M. Tomic-Canic, 2007. Cellular and molecular basis of wound healing in diabetes. J. Clin. Investigat., 117: 1219-1222. DOI: $10.1172 / \mathrm{JCI} 32169$

Brett, D.W., 2006. A discussion of silver as an antimicrobial agent: Alleviating the confusion. Ostomy/Wound Manage., 52: 34-41. PMID: 16464989

Burd, A., C.H. Kwok, S.C. Hung, H.S. Chan and H. $\mathrm{Gu}$ et al., 2007. A comparative study of the cytotoxicity of silver-based dressings in monolayer cell, tissue explant and animal models. Wound Repair Regenerat., 15: 94-104. DOI: 10.1111/j.1524-475X.2006.00190.X

Carmona, G.A., P. Hoffmeyer, F.R. Herrmann, J. Vaucher and O. Tschopp et al., 2005. Major lower limb amputations in the elderly observed over ten years: The role of diabetes and peripheral arterial disease. Diabetes Metabolism, 31: 449-454. DOI: $10.1016 / \mathrm{S} 1262-3636(07) 70215-\mathrm{X}$

Centers for Disease and Prevention, 2003. History of foot ulcer among persons with diabetes--United States, 2000-2002. MMWR Morbidity Mortality Weekly Report, 52: 1098-1102. PMID: 14614407 
Chan, D.C.W., D.H.F. Fong, J.Y.Y. Leung, N.G. Patil and G.K.K. Leung, 2007. Maggot debridement therapy in chronic wound care. Hong Kong Med. J., 13: 382-386. PMID: 17914145

Chang, S.L., 1971. Modern concept of disinfection. J. Sanitary Eng. Division, 97: 689-707.

Chowdhury, M.M., 1999. Honey: Is it worth rubbing it in? J. Royal Society Med., 92: 663-663. PMID: 10712103

Connor, H., 2008. Some historical aspects of diabetic foot disease. Diabetes/Metabolism Res. Rev., 24: S7-S13. DOI: 10.1002/dmrr.838

Cooper, R. and P. Molan, 1999. The use of honey as an antiseptic in managing pseudomonas infection. J. Wound Care, 8: 161-164.

DOI: 10.12968/jowc.1999.8.4.25867

Cooper, R., 2004. A review of the evidence for the use of topical antimicrobial agents in wound care. World Wide Wounds.

Cooper, R.A., P.C. Molan and K.G. Harding, 1999. Antibacterial activity of honey against strains of staphylococcus aureus from infected wounds. J. Royal Society Med., 92: 283-285. PMID: 10472280

Cooper, R.A., E. Halas and P.C. Molan, 2002a. The efficacy of honey in inhibiting strains of pseudomonas aeruginosa from infected burns. J. Burn Care Res., 23: 366-370. DOI: 10.1097/00004630-200211000-00002

Cooper, R.A., P.C. Molan and K.G. Harding, 2002b. The sensitivity to honey of Gram-positive cocci of clinical significance isolated from wounds. J. Applied Microbiol., 93: 857-863. DOI: 10.1046/j.1365-2672.2002.01761.x

Courtenay, M., J.C. Church and T.J. Ryan, 2000. Larva therapy in wound management. J. Royal Society Med., 93: 72-74.

Dang, C.N., Y.D.M. Prasad, A.J.M. Boulton and E.B. Jude, 2003. Methicillin-resistant staphylococcus aureus in the diabetic foot clinic: A worsening problem. Diabetic Med., 20: 159-161. DOI: $10.1046 /$ j.1464-5491.2003.00860.x

Demling, R.H. and L. Desanti, 2001. Effects of silver on wound management. Wounds, 13: 4-15.

Dritch, E.A., A.A. Marino, V. Malakanok and J.A. Albright, 1987. Silver nylon cloth: In vitro and in vivo evaluation of antimicrobial activity. J. Trauma Acute Care Surgery, 27: 301-304. PMID: 3560272

Du Toit, D.F. and B.J. Page, 2009. An in vitro evaluation of the cell toxicity of honey and silver dressings. J. Wound Care, 18: 383-389.

DOI: 10.12968/jowc.2009.18.9.44307

Easy, M., 2015. Suprasorb $\mathrm{x}+$ phmb made easy-products for practice. Schofield Publishing Ltd.
Eddy, J.J. and M.D. Gideonsen, 2005. Topical honey for diabetic foot ulcers. J. Fam. Pract., 54: 533-535.

Efem, S.E.E., 1988. Clinical observations on the wound healing properties of honey. Br. J. Surgery, 75: 679-681. DOI: 10.1002/bjs.1800750718

Fleck, C.A., 2006. Fighting infection in chronic wounds. Adv. Skin Wound Care, 19: 184-188.

Foda, N.H., H.M. El-laithy and M.I. Tadros, 2007. Implantable biodegradable sponges: Effect of interpolymer complex formation of chitosan with gelatin on the release behavior of tramadol hydrochloride. Drug Develop. Industrial Pharmacy, 33: 7-17. DOI: 10.1080/03639040600975188

Fong, J. and F. Wood, 2006. Nanocrystalline silver dressings in wound management: A review. Int. J. Nanomed., 1: 441-449. PMID: 17722278

Forrest, R.D., 1982. Early history of wound treatment. J. Royal Society Med., 75: 198-205. PMID: 7040656

French, V.M., R.A. Cooper and P.C. Molan, 2005. The antibacterial activity of honey against coagulasenegative staphylococci. J. Antimicrobial Chemotherapy, 56: 228-231. DOI: 228 10.1093/jac/dki193

Gemmell, C.G., D.I. Edwards, A.P. Fraise, F.K. Gould and G.L. Ridgway et al., 2006. Guidelines for the prophylaxis and treatment of Methicillin-Resistant Staphylococcus Aureus (MRSA) infections in the UK. J. Antimicrobial Chemotherapy, 57: 589-608. DOI: $10.1093 / \mathrm{jac} / \mathrm{dk1017}$

Gilliver, S., 2009. PHMB: A well-tolerated antiseptic with no reported toxic effects. J. Wound Care (NOV).

Horobin, A.J., K.M. Shakesheff and D.I. Pritchard, 2006. Promotion of human dermal fibroblast migration, matrix remodelling and modification of fibroblast morphology within a novel 3D model by lucilia sericata larval secretions. J. Investigative Dermatol., 126: 1410-1418. DOI: 10.1038/sj.jid.5700256

Jayakumar, R., M. Prabaharan, P.T.S. Kumar, S.V. Nair and H. Tamura, 2011. Biomaterials based on chitin and chitosan in wound dressing applications. Biotechnol. Adv., 29: 322-337. DOI: $10.1016 /$ j.biotechadv.2011.01.005

Jenkins, R., N. Burton and R. Cooper, 2011. Manuka honey inhibits cell division in methicillin-resistant staphylococcus aureus. J. Antimicrobial Chemotherapy, 66: 2536-2542.

DOI: $10.1093 / \mathrm{jac} / \mathrm{dkr} 340$

Kandemir, Ö., E. Akbay, E. Şahin, A. Milcan and R. Gen, 2007. Risk factors for infection of the diabetic foot with multi-antibiotic resistant microorganisms. J. Infect., 54: 439-445. DOI: $10.1016 /$ j.jinf.2006.08.013 
Khor, E. and L.Y. Lim, 2003. Implantable applications of chitin and chitosan. Biomaterials, 24: 2339-2349. DOI: $10.1016 / \mathrm{S} 0142-9612(03) 00026-7$

Klasen, H.J., 2000. A historical review of the use of silver in the treatment of burns. II. Renewed interest for silver. Burns, 26: 131-138.

DOI: 10.1016/S0305-4179(99)00116-3

Lacey, R.W. and A. Catto, 1992. Action of povidoneiodine against methicillin-sensitive and-resistant cultures of Staphylococcus aureus. Postgraduate Med. J., 69: S78-83. PMID: 8290463

Lansdown, A.B., 2002. Silver I: Its antibacterial properties and mechanism of action. J. Wound Care, 11: 125-130. DOI: 10.12968/jowc.2002.11.4.26389

Lansdown, A.B.G., 2004. A review of the use of silver in wound care: Facts and fallacies. Br. J. Nurs., 13: S6-S19. DOI: 10.12968/bjon.2004.13.Sup1.12535

Larkin, D.F.P., S. Kilvington and J.K.G. Dart, 1992. Treatment of acanthamoeba keratitis with polyhexamethylene biguanide. Ophthalmology, 99: 185-191. DOI: 10.1016/S0161-6420(92)31994-3

Leaper, D.J. and P. Durani, 2008. Topical antimicrobial therapy of chronic wounds healing by secondary intention using iodine products. Int. Wound J., 5: 361-368. DOI: 10.1111/j.1742-481X.2007.00406.x

Lee, D.W., H. Lim, H.N. Chong and W.S. Shim, 2009. Advances in chitosan material and its hybrid derivatives: A review. Open Biomaterials J., 1: 10-20. DOI: $10.2174 / 1876502500901010010$

Lee, J.H., 2003. Methicillin (oxacillin)-resistant staphylococcus aureus strains isolated from major food animals and their potential transmission to humans. Applied Environ. Microbiol., 69: 6489-6494. DOI: 10.1128/AEM.69.11.6489-6494.2003

Li, Q., E.T. Dunn, E.W. Grandmaison and M.F.A. Goosen, 1992. Applications and properties of chitosan. J. Bioactive Compatible Polymers, 7: 370-397. DOI: 10.1177/088391159200700406

Lipsky, B.A., 2008. New developments in diagnosing and treating diabetic foot infections. Diabetes/Metabolism Res. Rev., 24: S66-S71. DOI: $10.1002 / \mathrm{dmrr} .828$

Lipsky, B.A., A.R. Berendt, H.G. Deery, J.M. Embil and W.S. Joseph et al., 2004. Diagnosis and treatment of diabetic foot infections. Clin. Infect. Dis., 39: 885-910. DOI: $10.1086 / 424846$

Loh, J.V., S.L. Percival, E.J. Woods, N.J. Williams and C.A. Cochrane, 2009. Silver resistance in MRSA isolated from wound and nasal sources in humans and animals. Int. Wound J., 6: 32-38.

DOI: $10.1111 /$ j.1742-481X.2008.00563.X
Maeda, Y., A. Loughrey, J.A.P. Earle, B.C. Millar and J.R. Rao et al., 2008. Antibacterial activity of honey against Community-Associated MethicillinResistant Staphylococcus Aureus (CA-MRSA). Complementary Therapies Clin. Pract., 14: 77-82. DOI: $10.1016 /$ j.ctcp.2007.11.004

Mandal, M.D. and S. Mandal, 2011. Honey: Its medicinal property and antibacterial activity. Asian Pacific J. Tropical Biomed., 1: 154-160. DOI: 10.1016/S2221-1691(11)60016-6

Maple, P.A.C., J.M.T. Hamilton-Miller and W. Brumfitt, 1992. Comparison of the in-vitro activities of the topical antimicrobials azelaic acid, nitrofurazone, silver sulphadiazine and mupirocin against methicillin-resistant staphylococcus aureus. J. Antimicrobial Chemotherapy, 29: 661-668. DOI: $10.1093 /$ jac/29.6.661

Mayer, D.A. and M.J. Tsapogas, 1993. Povidone iodine and wound-healing-a critical-review. Wounds-A Compendium Clin. Res. Pract., 5: 14-23.

McDonnell, G. and A.D. Russell, 1999. Antiseptics and disinfectants: Activity, action and resistance. Clin. Microbiol. Rev., 12: 147-179.

Mendes, J.J., A. Marques-Costa, C. Vilela, J. Neves and N. Candeias et al., 2012. Clinical and bacteriological survey of diabetic foot infections in Lisbon. Diabetes Res. Clin. Pract., 95: 153-161. DOI: $10.1016 /$ j.diabres.2011.10.001

Mertz, P.M., M.F. Oliveira-Gandia and S.C. Davis, 1999. The evaluation of a cadexomer iodine wound dressing on methicillin resistant staphylococcus aureus (MRSA) in acute wounds. Dermatologic Surgery, 25: 89-93.

DOI: $10.1046 / j .1524-4725.1999 .08055 . x$

Mezzana, P., 2007. Clinical efficacy of a new chitin nanofibrils-based gel in wound healing. Acta Chirurgiae Plasticae, 50: 81-84. PMID: 19263641

Michaels, J.A., W.B. Campbell, B.M. King, J. Macintyre and S.J. Palfreyman et al., 2009. A prospective randomised controlled trial and economic modelling of antimicrobial silver dressings versus nonadherent control dressings for venous leg ulcers: The vulcan trial. Health Technol. Assess., 13: 1-114. DOI: $10.3310 /$ hta 13560

Molan, P.C., 1992. The antibacterial activity of honey: 2. Variation in the potency of the antibacterial activity. Bee World, 73: 59-76.

Molan, P.C., 1999. The role of honey in the management of wounds. J. Wound Care, 8: 415-418. PMID: 10808853

Molan, P.C., 2002. Re-introducing honey in the management of wounds and ulcers-theory and practice. Ostomy Wound Manage, 48: 28-40. PMID: 12426450 
Molan, P.C., 2006. The antibacterial activity of honey: 1. the nature of the antibacterial activity. Bee World, 73: 5-28.

Moore, K. and D. Gray, 2007. Using phmb antimicrobial to prevent wound infection. Wounds UK, 3: 96-96.

Moore, O.A., L.A. Smith, F. Campbell, K. Seers and H.J. McQuay et al., 2001. Systematic review of the use of honey as a wound dressing. BMC Complementary Alternative Med., 1: 2-2.

DOI: $10.1186 / 1472-6882-1-2$

Motta, G.J. and D. Trigilia, 2005. The effect of an antimicrobial drain sponge dressing on specific bacterial isolates at tracheostomy sites. Ostomy/Wound Manag., 51: 60-62. PMID: 15695836

Mueller, S.W. and L.E. Krebsbach, 2008. Impact of an antimicrobial-impregnated gauze dressing on surgical site infections including methicillinresistant Staphylococcus aureus infections. Am. J. Infect. Control, 36: 651-655.

DOI: $10.1016 /$ j.ajic.2007.12.005

Müller, G. and A. Kramer, 2008. Biocompatibility index of antiseptic agents by parallel assessment of antimicrobial activity and cellular cytotoxicity. J. Antimicrobial Chemotherapy, 61: 1281-1287.

DOI: $10.1093 / \mathrm{jac} / \mathrm{dkn} 125$

Mumcuoglu, K.Y., 2012. The use of maggot debridement therapy in the treatment of chronic wounds in hospitalised and ambulatory patients. J. Wound Care, 21: 78-85. PMID: 22584527

Murali, T.S., B. Paul, H. Parikh, R.P. Singh and S. Kavitha et al., 2014. Genome sequences of four clinical staphylococcus aureus strains with diverse drug resistance profiles isolated from diabetic foot ulcers. Genome Announcements, 2: e00204-00214. DOI: 10.1128/genomeA.00204-14

Olaitan, P.B., O.E. Adeleke and O.O. Ola, 2007. Honey: A reservoir for microorganisms and an inhibitory agent for microbes. Afr. Health Sci., 7: 159-165. PMID: 18052870

Ovington, L.G., 2001. Hanging wet-to-dry dressings out to dry. Home Healthcare Nurse, 19: 477-483.

Parnés, A. and K.M. Lagan, 2007. Larval therapy in wound management: A review. Int. J. Clin. Pract., 61: 488-493. DOI: $10.1111 / \mathrm{j} .1742-1241.2006 .01238 . \mathrm{x}$

Percival, S.L., P.G. Bowler and D. Russell, 2005. Bacterial resistance to silver in wound care. J. Hospital Infect., 60: 1-7. DOI: $10.1016 /$ j.jhin.2004.11.014

Porrero, M.C., A. Valverde, P. Fernández-Llario, A. Díez-Guerrier and A. Mateos et al., 2014. Staphylococcus aureus carrying mecC gene in animals and urban wastewater, Spain. Emerg. Infect. Dis., 20: 899-899. DOI: 10.3201/eid2005.130426
Ramsey, S.D., K. Newton, D. Blough, D.K. McCulloch and N. Sandhu et al., 1999. Incidence, outcomes and cost of foot ulcers in patients with diabetes. Diabetes Care, 22: 382-387. DOI: 10.2337/diacare.22.3.382

Rayner, C. and W.J. Munckhof, 2005. Antibiotics currently used in the treatment of infections caused by staphylococcus aureus. Int. Med. J., 35: S3-S16. DOI: 10.1111/j.1444-0903.2005.00976.X

Rice, K.C., B.A. Firek, J.B. Nelson, S.J. Yang and T.G. Patton et al., 2003. The staphylococcus aureus cidab operon: Evaluation of its role in regulation of murein hydrolase activity and penicillin tolerance. $\mathrm{J}$. Bacteriol., 185: 2635-2643.

DOI: $10.1128 / J B .185 .8 .2635-2643.2003$

Roberts, A.D. and G.L. Simon, 2012. Diabetic foot infections: The role of microbiology and antibiotic treatment. Seminars Vascular Surgery, 25: 75-81. DOI: 10.1053/j.semvascsurg.2012.04.010

Robson, M.C., 1997. Wound infection: A failure of wound healing caused by an imbalance of bacteria. Surgical Clin. North Am., 77: 637-650. DOI: 10.1016/S0039-6109(05)70572-7

Russell, A.D., F.R.C. Path, F.R.P. S and W.B. Hugo, 1994. 7 antimicrobial activity and action of Silver. Progress Med. Chem., 31: 351-370. DOI: 10.1016/S0079-6468(08)70024-9

Shankar, E.M., V. Mohan, G. Premalatha, R.S. Srinivasan and A.R. Usha, 2005. Bacterial etiology of diabetic foot infections in south India. Eur. J. Internal Med., 16: 567-570.

DOI: $10.1016 /$ j.ejim.2005.06.016

Sherman, R.A., C.E. Shapiro and R.M. Yang, 2007. Maggot therapy for problematic wounds: Uncommon and off-label applications. Adv. Skin Wound Care, 20: 602-610. DOI: 10.1097/01.ASW.0000284943.70825.a8

Sibbald, R.G., H. Orsted, G.S. Schultz, P. Coutts and D. Keast, 2003. Preparing the wound bed 2003: Focus on infection and inflammation. Ostomy Wound Manage., 49: 24-51. PMID: 14652411

Simmons, S.W., 1935. The bactericidal properties of excretions of the maggot of Lucilia sericata. Bull. Entomol. Res., 26: 559-563. DOI: $10.1017 / \mathrm{S} 0007485300036907$

Simon, A., K. Traynor, K. Santos, G. Blaser and U. Bode et al., 2009. Medical honey for wound carestill the 'latest resort'? Evidence-Based Complementary Alternative Med., 6: 165-173. DOI: $10.1093 /$ ecam/nem 175

Sinclair, R.D. and T.J. Ryan, 1993. A great war for antiseptics. Australasian J. Dermatol., 34: 115-118. DOI: 10.1111/j.1440-0960.1993.tb00878.x 
Singh, N.M., S.K. Bhatia and G. Singh, 2014. Maggots therapy in facilitating wound debridement: Present status. Med. J. Dr. DY Patil University, 7: 639-642. DOI: $10.4103 / 0975-2870.140476$

Sørensen, O.E., J.B. Cowland, K. Theilgaard-Mönch, L. Liu and T. Ganz et al., 2003. Wound healing and expression of antimicrobial peptides/polypeptides in human keratinocytes, a consequence of common growth factors. J. Immunol., 170: 5583-5589. DOI: 10.4049/jimmunol.170.11.5583

Steenvoorde, P., C.E. Jacobi and J. Oskam, 2005. Maggot debridement therapy: Free-range or contained? An in-vivo study. Adv. Skin Wound Care, 18: 430-435.

Subrahmanyam, D.M., 1991. Topical application of honey in treatment of burns. Br. J. Surgery, 78: 497-498. DOI: 10.1002/bjs.1800780435

Subrahmanyam, M., 1998. A prospective randomised clinical and histological study of superficial burn wound healing with honey and silver sulfadiazine. Burns, 24: 157-161. DOI: $10.1016 / \mathrm{S} 0305-4179(97) 00113-7$

Sun, K. and Z.H. Li, 2011. Preparations, properties and applications of chitosan based nanofibers fabricated by electrospinning. Express Polymer Lett., 5: 342-361. DOI: $10.3144 /$ expresspolymlett.2011.34

Sundberg, J. and R. Meller, 1997. A retrospective review of the use of cadexomer iodine in the treatment of chronic wounds. Wounds-A Compendium Clin. Res. Pract., 9: 68-86.

Tantawi, T.I., Y.M. Gohar, M.M. Kotb, F.M. Beshara and M.M. El-Naggar, 2007. Clinical and microbiological efficacy of MDT in the treatment of diabetic foot ulcers. J. Wound Care, 16: 379-383. DOI: 10.12968/jowc.2007.16.9.27868

Tao, Z., A. Shi and J. Zhao, 2015. Epidemiological perspectives of diabetes. Cell Biochem. Biophys. 73: 181-185. DOI: $10.1007 / \mathrm{s} 12013-015-0598-4$

Tentolouris, N., G. Petrikkos, N. Vallianou, C. Zachos and G.L. Daikos et al., 2006. Prevalence of methicillin-resistant Staphylococcus aureus in infected and uninfected diabetic foot ulcers. Clin. Microbiol. Infect., 12: 186-189.

DOI: 10.1111/j.1469-0691.2005.01279.x

Thomas, S. and P. McCubbin, 2003a. A comparison of the antimicrobial effects of four silver-containing dressings on three organisms. J. Wound Care, 12: 101-107. DOI: 10.12968/jowc.2003.12.3.26477
Thomas, S. and R. McCubbin, 2003b. An in vitro analysis of the antimicrobial properties of 10 silvercontaining dressings. J. Wound Care, 12: 305-308. DOI: 10.12968/jowc.2003.12.8.26526

Tredget, E.E., H.A. Shankowsky, A. Groeneveld and R. Burrell, 1998. A matched-pair, randomized study evaluating the efficacy and safety of acticoat* silver-coated dressing for the treatment of burn wounds. J. Burn Care Res., 19: 531-537.

Vardi, A., Z. Barzilay, N. Linder, H.A. Cohen and G. Paret et al., 1998. Local application of honey for treatment of neonatal postoperative wound infection. Acta Paediatr., 87: 429-432. DOI: $10.1111 /$ j.1651-2227.1998.tb01473.x

Visavadia, B.G., J. Honeysett and M.H. Danford, 2008. Manuka honey dressing: An effective treatment for chronic wound infections. Br. J. Oral Maxillofacial Surgery, 46: 55-56.

DOI: 10.1016/j.bjoms.2006.09.013

Wielders, C.L.C., A.C. Fluit, S. Brisse, J. Verhoef and F.J. Schmitz, 2002. mecA gene is widely disseminated in staphylococcus aureus population. J. Clin. Microbiol., 40: 3970-3975. DOI: 10.1128/JCM.40.11.3970-3975.2002

Wood, B., M. Rademaker and P. Molan, 1997. Manuka honey, a low cost leg ulcer dressing. New Zealand Med. J., 110: 107-107. PMID: 9137314

Wright, J.B., K. Lam and R.E. Burrell, 1998. Wound management in an era of increasing bacterial antibiotic resistance: A role for topical silver treatment. Am. J. Infect. Control, 26: 572-577. DOI: 10.1053/ic.1998.v26.a93527

Yin, H.Q., R. Langford and R.E. Burrell, 1999. Comparative evaluation of the antimicrobial activity of acticoat antimicrobial barrier dressing. J. Burn Care Res., 20: 195-200.

Ziffren, S.E., H.E. Heist, S.C. May and N.A. Womack, 1953. The secretion of collagenase by maggots and its implication. Annals Surgery, 138: 932-932.

Zubair, M., A. Malik and J. Ahmad, 2012. Incidence, risk factors for amputation among patients with diabetic foot ulcer in a north Indian tertiary care hospital. Foot, 22: 24-30.

DOI: $10.1016 /$ j.foot.2011.09.003 